\title{
Transnational education: Developing graduates in Malaysia for a globalized world
}

\author{
Beena Giridharan and Peter Ling \\ Curtin University, Miri, Sarawak, Malaysia \\ beena@curtin.edu.my; beena.giridharan@curtin.edu.au \\ Swinburne University of Technology, Melbourne, Australia \\ pling@swin.edu.au
}

\section{ARTICLE INFO}

Article history

ReCEIVED: 03-Sep-2019

REVISED: $14-$ Oct-2019

ACCEPTED: 06-Dec-2019

PUBLISHED: $16-$ Dec-2019

*Corresponding Author

Email: beena@curtin.edu.my

\begin{abstract}
In recent years we have seen the establishment of a number of international offshore campuses in Malaysia and Singapore which in turn has spurred the growth of transnational education (TNE) offerings in the region. In Malaysia, TNE was facilitated by the introduction of the Private Higher Educational Institutions Act 1996 or Act 555, which provided the governing framework for the privatization of higher education in Malaysia (Sivalingam, 2006).
\end{abstract}

In this paper we ask whether transnational education as practiced in Malaysia has a particular contribution to one aspect of the student experience - preparing graduates for an increasingly globalized world. We considered the contribution that internationalization of curriculum and the international experience staff bring to the development of graduate capabilities suited to a globalized world. The opportunities that transnational education bring to the learning experiences of students were studied through an examination of approaches to teaching adopted by the academics delivering programs. The paper reports on an empirical study conducted in Australia and on transnational campuses in Malaysia to illustrate the extent to which current educational practice equips students to operate beyond national boundaries and suggest what needs to happen in order to realize the potential of transnational education for preparing students to operate in a globalized environment.

Keywords: Globalization, transnational education, internationalisation of curriculum, branch campuses

\section{Introduction}

Accepting the assertion of President Clinton of the United States, that "Globalization is not something that we can hold off or turn off. It is the economic equivalent of a force of nature, like wind or water" (U.S. Government Information, 2000), this paper is concerned with the contemporary higher education imperative to produce graduates capable of operating in an increasingly globalized world. The form of globalization is, however, dynamic, with implications for educational institutions preparing graduates for a globalized world. Baldwin states:

This future is coming incredibly fast and in ways few people expect The 'old' globalization was about things we make. The future globalization will be quite different: it will also be about things we do. ...We need to prepare ourselves for the future of globalization by building up skills. (Baldwin, 2019, p.3)

Preparing students for a globalized world is a mission taken on by many universities as is indicated by the fact 
that QS university rankings, incorporates in its measures the international experience of academics (University Alliance, 2014). This paper is focused on one form of provision of higher education, transnational education, and looks at both theoretical potential and current practice based on an empirical study.

\section{Key concepts - transnational education, internationalisation, globalization}

A report sponsored by the British Council and the German Academic Exchange Service refers to 'TNE terminology chaos' (Knight and McNamara, 2017, p.1). The meaning of transnational education adopted in this paper is an established one. Transnational education refers here to an arrangement in which a student studies for an award granted by a university based in a country other than the country in which the student is studying (Global Alliance for Transnational Education, 1997, p.1). Transnational education is expanding while modes of delivery and policy approaches continue to evolve on a country-by-country basis (McNamara, Knight, \& Fernandez-Chung, 2013). There is a range of motives for increased engagement in transnational education. China, for instance, has been said to use transnational education for academic capacity building and knowledge transfer from foreign partners. Malaysia, on the other hand, looks to international student recruitment and transnational education as a source of revenue (McNamara, Knight, \& Fernandez-Chung, 2013).

Numerous organisational arrangements for transnational education are possible from branch campuses to partnerships, franchises, mutual recognition of awards, study abroad and student exchange programs, and distance education. The term transnational education, then, embraces a range of possibilities with many terms being employed to describe them; 'over 40 different terms are being used to describe international programme and provider mobility' (Knight and McNamara, 2017, p.1). The present paper relates the branch campus model of transnational education. 'The last decade has seen a steady increase in the number of branch campuses and the development of internationally co-founded and joint institutions' (Knight and McNamara, 2017, p.7). The way in which educational decision-making plays out in this form of transnational education is pertinent to the present paper. The classification framework provided by the British Counciland the German Academic Exchange Service distinguishes two major approaches to transnational education:

1. Independent transnational education provision in which the foreign higher education provider is primarily responsible for the design, delivery and external quality assurance of their academic programmes and qualifications being offered in another country.

2. Collaborative transnational education provision in which a foreign higher education provider and host country provider work together on the design, delivery and/or external quality assurance of the academic programmes.

The empirical component of the present study was undertaken on Malaysian transnational campuses of two Australian institutions, where the arrangement falls essentially in the first category of transnational education. This, however, does not mean that all educational decisions are made offshore; indeed, arrangements differed by program and ranged from foreign institution control of curriculum, teaching strategies and assessment to various forms of shared decision-making, and, in some instances, to local generation of programs (Mazzolini, Yeo, Giridharan, Goerke, Ling, and Lueckenhausen, 2012).

Internationalisation of higher education referred in the 1990s to specific initiatives such as inclusion of 'international studies, international educational exchange and technical cooperation' (Knight, 2004). The concept has broadened to 'the incorporation of an international and intercultural dimension into the preparation, delivery and outcomes of a program of study' both for domestic students and for 'foreign' students (Leask, 2009, p. 209).

Globalization and global interconnectedness have had a range of impacts on higher education. Features of the globalized environment that impact on higher education include: professionals engaging with one another in a fast and efficient manner across borders; and 'the demand for higher education and courses and programs that offer skills and knowledge and competencies that have currency in the job market in a globalized world' (Van Damme, 2011, p.2). The skills and knowledge required with changes in the lobal environment. Baldwin (2019) sees a future in which 'Digital technology is making it possible for 'tele-migrants' sitting in one country to do things in another country' (p.3). Responses to the globalized environment include: 'the proliferation of a number of higher education partnerships and arrangements between institutions across countries'; and 'institutional missions that includes the notion of preparing students for a globalized world' (Chow, 2013). An issue that arises is how well these international institutional arrangement prepare students for life and work in a globalized environment. 


\section{The issue and research question addressed}

The specific issue addressed in this paper is 'how well does transnational higher education as practiced through transnational campuses in Malaysia contribute to the preparation of students for life and work in a globalized world?' In working towards an answer we ask 'what could this form of transnational education potentially contribute?', 'what is the current practice?' and 'what would need to happen to realise the potential?' In exploring these questions we examine the form of internationalisation adopted by transnational campuses, curriculum design arrangements and the teaching practices adopted by academics involved.

\section{Potential of transnational education to contribute to the preparation of students for a globalized world}

Transnational education by definition involves provision of education in more than one country. Hence academics at transnational education campuses have to consider more than one national context.

Students on transnational education campuses can be exposed to alternative cultures, more than one understanding of concepts, to alternative forms of learning and teaching practice, and to diverse learning environments.

Transnational education has the potential to offer students the opportunity to attain graduate attributes that home universities are working towards. For instance, 'Global citizenship' is an attribute that is fairly common across Australian universities (Barrie, 2009, p.28). At transnational campuses, students in engineering courses that include engineering site visits as part of the course experience may conduct virtual visits of engineering sites in Australia involving advanced technology, as well as conduct physical site visits in transnational campus countries to consider issues from a variety of standards and practices. With the introduction of new technologies on the uptake in most Australian campuses, the opportunities for a range of multicultural perspectives and cross-cultural experiences may gain more traction. 'Cultural understanding' is another graduate attribute that transnational campuses can contribute towards utilizing their diversity of students and faculty and active interflow of ideas and views. Contextualisation of courses could assist in developing this graduate attribute. Internationalized curricula that is focussed on student learning is characterized by two central criteria; one is that, it will transpire within the setting of different cultures and practices of the disciplines, and further that faculty that are yet to gain knowledge of internationalized curricula and skills will be supported by expert facilitators for defining intended internationalized learning outcomes and would assist all students to achieve the learning outcomes ( Leask, 2014).

\section{Internationalisation and globalization}

The research element of this paper is informed by the concept of transnational education, discussed above, internationalisation of education, and the concept of globalization in relation to higher education. The empirical element of the paper, and the exploration of current practice, is based on an Australian Office for Learning and Teaching project Learning without borders, which was conducted by the authors (see Mazzolini et al, 2012). The project focused particularly on the provision of higher education through transnational campuses.

The project was charged with recommending approaches to international and cross-cultural teaching excellence in a transnational education context, which is pertinent to the present topic, i.e., the preparation of graduates for a globalized world.

\section{Research methods employed}

Methodologically, a case study approach is taken in this paper (Yin, 2013) with a view to adding to the understanding of the potential of the type of transnational education addressed, to contribute to preparation of graduates for a globalized world. Taking a case study approach means the findings are an interpretation, and conclusions reached may not be generalisable to other contexts. While data collection has included responses from academics engaged in a range of transnational education categories, the focus of the study reported here has been on the Australian campuses and the Sarawak, Malaysian campuses of Curtin University and Swinburne University of Technology.

The methods employed in exploring the research questions included the following: web searches, review of policies and procedures, surveys using questionnaires, and conducting individual interviews and focus groups.

Firstly, transnational education policies and procedures of the institutions participating in the study, were used to identify arrangements established for the provision of transnational education and policies on internationalization, including internationalization of curriculum. An 
online survey with 22 items addressed the understanding of internationalization, and of internationalization of curriculum, and learning and teaching practices by involved academics. The questionnaire investigated experiences in working in offshore locations and views on what worked well and what did not. Sixty four (64) completed questionnaires were received from respondents.

Additionally, individual interviews and focus group interviews were conducted to further explore the experiences of academic leaders working in a transnational education context, and understand their views on how transnational education and internationalisation policies and procedures could best address internationalization of curriculum.

Individual interviews were conducted with thirty two (32) academic staff who held senior positions and were in leadership roles at Curtin and Swinburne university, located at both the home and transnational campuses.

In addition, Four (4) focus group interviews were conducted on the Malaysian campuses in conjunction with project workshops. The student learning experience element of the research questions was addressed indirectly using observations of transnational campus academics and by comparing policies, procedures and practices with opportunities for contextualisation of learning and assessment. The paper is informed by the range of data derived and the extracts from responses quoted in this paper are derived from interviews.

\section{Current practice - findings}

The study reported on here gathered data from home campus and local academics and institutional leaders engaged in transnational education delivery, mostly through branch campuses. The delivery includes faceto-face input by academics based at a home campus and substantial delivery by local academics. In all cases a balance had to be struck between home and local academics on educational decision-making; in particular who specified the intended learning outcomes and who determined the curriculum content, the learning and teaching methods, the design of learning resources, the assessment tasks and assessment grades.

\section{Theoretical Constructs}

The term locus of control is used in the project in an organisational sense describing possibilities for division of responsibilities in TNE between staff on the home campus and those on transnational campuses.

The term locus of control is also used in psychology to refer to the impact on an individual's behaviour of the individual's understanding of whether a matter is within one's own control or is controlled externally to the individual.

While the expression locus of control is used in the project to describe/categorise TNE situations, the impact on individuals involved in can depend, at least in part, on their understanding of whether particular TNE decisions are within their area of control or are external to them.

Rotter ( 1966) postulated that when individuals believed that the results of their behaviour were governed by destiny or by powerful others, it indicated that they believed in an external locus of control, whereas when individuals thought that they themselves were responsible for the consequences of their behaviour, they believed in an internal locus of control. In the context of TNE, from a transnational campus perspective 'locus of control' could be interpreted as the power or control, unit coordinators and course coordinators at home campuses exercised for quality assurance in the delivery of units and courses at offshore campuses. From the empirical data gathered from transnational campus academic staff in the ALTC-Learning without borders project, younger academics who had little exposure to teaching in international higher education settings, in particular, believed that the unit was not in their control as opposed to mature and more experienced academic staff at transnational campuses who had worked internationally in higher education settings. The social learning perspective referred to by Rotter ( 1966) could be seen to be in play here. It could be claimed that individuals who had higher internal locus of control took more responsibility for the successful delivery of units at the transnational campuses, than individuals who believed that successful delivery of the units rested mainly with unit coordinators based at the home campus. This may also be relevant to leadership abilities among transnational campus academics. Academic staff who demonstrated leadership capacity, discerned via statements gathered in the empirical data, could be seen to have higher internal locus of control.

In the cases studied we found a variety of approaches to the balance of decision-making. We divided these into four broad approaches: home institution control; limited transnational campus control; distributed control; and local campus control. How these approaches played out in practice is detailed below. 
Under the home institution control model, curriculum design, learning resources and assessment were determined by home campus academics and were the same for students at any location. It might be substantially delivered by home campus academics on a fly-in-fly-out basis, with some local tutors, or might be delivered by local academics under guidance from the home campus academics.

At the transnational campus end a local academic stated:

The package come with all the outcomes, assessments, PowerPoint slides and other documents, I went over the whole thing and modified a little bit.

This model was applied mostly in undergraduate programs during the initial stages of branch campus operations at both Swinburne and Curtin.

In the limited transnational campus control model, the program is substantially delivered by local academics, maybe with some visits from home campus staff. There were opportunities for contextualisation of learning activities and/or assessment items. Assessment or a sample of assessment is moderated by home campus academics. In engineering, for example, a Deputy Dean on the home campus stated:

We're really striving to say that the two programs are equivalent but you don't have to be identical. So for example, in engineering, codes of practices are quite important and the Malaysians will use their codes of practice there but also cross reference with our ones as well. They'll use some of the design examples which are more about the Malaysian context than an Australian context.

In this model local input may be modest. In the experience of a transnational campus Unit Convener:

Staff may introduce their way of presenting but by and large the content of the teaching material comes from [the home campus]. Staff are free to present it in their own way. Staff have absolute freedom to do what they want but must conform with material and content.

The limited transnational campus model was applied in the undergraduate programs after two or three years of running the course and the home campus unit coordinators had been working with tansnational campus unit leaders.

Programs under the distributed control model are substantially delivered by local academics. Elements of the curriculum along with learning resources might be designed locally. Learning and teaching activities and assessment can be contextualised. Local educational decisions are constrained only by an obligation to attain the same learning outcomes. This model may include sample assessment moderation by the home institution. A home campus Deputy Dean provided a picture of the way this plays out:

Before the start of semester we each swap our unit outlines across to ensure that our assessment for example is compatible, our learning objectives are compatible. They will provide to us with what their major assignment is, or what their exam is and we'll just QA (quality assure) that and say "yep, that's ok".

A local campus Unit Convener described the operation in these terms:

I get some material from Australia, like unit outline, slides, etc., I generally just take it as guideline and I develop my own material, my own unit outline, and then I get approved, get suggestions from my counterpart. Teaching method also, I adopt my own.

Local campus control sometimes applies. Here the curriculum and delivery decisions are determined by local academics subject to accreditation by the home institution. This could be an award, a major study or an elective offered on the local campus only. In some cases these studies might be taken by home campus students though 'study abroad' options. Only a couple of instances were found in this study. A major entitled 'Borneo Studies' developed on the Curtin University Sarawak campus provides an example. One branch campus Unit Convener reported 'we are not entirely free of curriculum development responsibilities'.

In the distributed control model the international campus is considered as a mature campus by the home campus and relationships between the home campus and transnational campus are often shaped by structures and standards demanded by qualifications agencies and professional accrediting bodies in both countries. For example, TEQSA (Tertiary Education Quality Standards Agency), the body that states that students studying in Australian campuses, whether they are home campuses or transnational campuses, must have similar learning experiences. This ensures comparable quality of programs and delivery systems. In addition, the transnational campuses have to adhere to standards set by their home countries. The Malaysian Qualifications Agency (MQA) often requires offshore campuses to demonstrate autonomy in all the academic processes such as development of new courses to cater to regional needs, involvement of academics at the trasnational campus in developing 
curriculum, assessments, and grading systems. This allows for academic growth and potential for collaborative working models to be developed through the distributed control model. In current higher education contexts in which there are changing expectations for student outcomes and accelerated technological advancements, graduates require specific skills, awareness and knowledge to successfully traverse a challenging and interconnected world ( Williams \& Lee, 2015).

At Curtin University, there are attempts to engage with students across the transnational campuses through the use of distributed learning which sees joint facilitation of learning and teaching sessions in real-time with the campuses being in the same time zones. Understandably, these engagements require academics to be cognizant of intercultural pedagogies.

Academics interviewed indicated that the locus of control adopted had an impact on the student learning experience. This could be pertinent to preparing students to operate in an increasingly globalized world. Students on transnational education campuses studying for an Australian award have their horizons broadened. However, a high level of home determination of curriculum content, educational resources, teaching and learning activities, and assessment items and grading can disadvantage students at transnational education locations who are unfamiliar with the Australia context of the learning design. From the point of view of transnational students some localised content and learning activities, along with some local assessment items, may be more pertinent allowing account to be taken of the experiences and context of local students, which is desirable if one adopts a constructivist understanding of learning processes. Some transnational campus adaptations may also prove pertinent to internationalisation of curriculum on the home campus. Consequences for student learning are summarised in Table 1.

\section{Realising the potential - discussion}

The opportunity to realize the potential for preparing graduates for a globalized world depends on working toward internationalization of curriculum in its fullest sense at campuses at home and overseas. In transnational education it is also best facilitated where students experience a mix of local and home campus content and learning activities, assessed in a manner that respects the local context while meeting the requirements of the awarding institution, the home campus. This aligns with the Malaysian Qualifications Agency requirement of evidence of local educational decision-making (Malaysian Qualifications Agency, 2010, Section 2).

Each of the approaches to educational decision-making that we encountered has the potential to make a contribution to widening the knowledge-base and the cultural experiences of students beyond that experienced by students based only at a home campus. It is, however, the approaches that allow for some contextualisation of learning resources, learning activities and assessment that offer most in preparation of graduates for a globalized world. It is approach two - limited local input - and particularly approach three - distributed control - that best provide an internationalised experience for students. Approach four - local campus control - can provide a powerful international experience for home campus students undertaking it on a study-abroad basis but this model does little for local students on a transnational education campus apart from providing an element of

Table 1: The locus of control and the student learning experience

\begin{tabular}{ll}
\hline The locus of control & Consequences for the student learning experience \\
\hline 1. Home institution control & $\begin{array}{l}\text { Learning experiences are not tailored to the experience and context of local students, which may disadvantage } \\
\text { students on the transnational education campus. The arrangement does provide local students with learning } \\
\text { experiences derived from a different culture. }\end{array}$ \\
$\begin{array}{l}\text { 2. Limited transnational } \\
\text { campus control }\end{array}$ & $\begin{array}{l}\text { The unit and assessment are the same regardless of whoever delivers the unit. Learning and teaching activities } \\
\text { may be contextualised to be more relevant to local students. } \\
\text { to those attained by home institution students, usually achieved by using the same assessment. Local students } \\
\text { engage in learning experiences related to both the home campus culture and the local culture. } \\
\text { L. Distributed control }\end{array}$ \\
$\begin{array}{l}\text { Learning experiences can be tailored to local students. } \\
\text { ment of Australian content. Local students then engage in learning experiences related to both the home campus } \\
\text { culture and the local culture. } \\
\text { Learning experiences can be tailored to local students. For local students the experience may be less globalized } \\
\text { than curriculum controlled by the home campus. For students from the home campus taking the studies on a } \\
\text { study-abroad arrangement this approach could provide a rich international learning experience. }\end{array}$
\end{tabular}


their program that provides a better appreciation of their own context.

\section{Conclusion}

Internationalisation of curriculum, understood in its widest sense, is designed to prepare graduates for a globalized world. For students on home campuses and transnational education campuses available resources can be used to internationalise the student learning, for example, by actively sharing experience of international staff and international students on campus and using student exchanges and study aboard opportunities as well as engaging in online interactions. This is most often achieved via the learning management systems that home and transnational campuses share for learning and teaching delivery as well as the opportunities presented during academic visits to home and transnational campus academics.

The task in this paper was to address the question "how best can transnational higher education operations contribute to the preparation of students for the life and work in a globalized world?' We looked at the potential of transnational education to contribute and noted that by definition transnational education involves students in an international learning context. It can expose students to alternative cultures, to more than one understanding of concepts, to alternative forms of practice, and to more diverse learning environments. We then looked at practice in transnational education with particular reference to provision of transnational education through offshore campuses and noted that the diversity of the students' learning experiences on transnational education campuses depended, at least in part, on the locus of control; where decisions about curriculum content, learning resources, learning activities, and assessment were made. Approaches to transnational education that allow for local contextualisation of the learning experience along with elements of curriculum meeting the requirements of the awarding institution, the home campus, offer the best prospect of preparing graduates for a globalized world.

The limitations of this study need to be acknowledged. It is based largely on the experience of delivery through two transnational campuses. Transnational campuses, which engage academics under the auspices of the awarding institution, provide an environment in which local decision-making can readily apply. However, delivery through transnational campuses models or via other forms of transnational education - such as direct delivery by academics from a home campus, partnerships, franchising and particularly study-abroad schemes - may be associated with other opportunities for preparing graduates for a globalized world.

On the basis of the study reported here we conclude that the development of global citizenship can be realized through utilizing the resources provided by the home and transnational education campuses, inputs provided by staff and students with international experience, by extending the classroom to embrace the world beyond, and in relations between home and transnational campuses, and by adopting a distributed model of control of curriculum and teaching and learning activities.

\section{Acknowledgements}

We wish particularly to acknowledge contributions to the original Learning without borders project of Shelley Yeo and Veronica Goerke of Curtin University, Perth, Australia and Gillian Lueckenhausen, Melbourne, Australia. Support for the Learning without borders project has been provided by the Australian Government, Office for Learning and Teaching. The views expressed in this report do not necessarily reflect the views of the Australian Government Office for Learning and Teaching

\section{References}

Bandura, A. (1977). Social Learning Theory. New York: General Learning Press.

Barrie, S., Hughes, C and Smith, C. (2009) The National Graduate Attributes Project: integration and assessment of graduate attributes in curriculum. Australian Learning and Teaching Council, Sydney.

Bates, A.W. (2000). Managing technological change: Strategies for college and university leaders. San Francisco: Jossey-Bass.

Berge, Z.L., Collins, M., \& Dougherty, K. (2000). Design guidelines for web-based coursed. In B. Abbey (Ed.), Instructional and cognitive impacts of web-based education (pp. 32-40). Hershey, PA: Idea Group Publishing.

Bolden, R., Gosling, J., Marturano, A. and Dennison, P ( 2003). A Review of Leadership Theory and Compterncy Frameworks, University of Exeter. Retrieved 20 January 2014 at http://www2.fcsh.unl.pt/docentes/luisrodrigues/textos/ Lideran\%C3\%A7a.pdf

Caruana, V. \& Hanstock, J., 2003. Internationalising the Curriculum: From Policy to Practice. In Education in a Changing Environment 17th-18th September 2003. Salford: University of Salford. http://www.ece.salford.ac.uk/proceedings/ papers/vc_03.rtf 
Chandler, T. (2001). Outback and in again: A new graduate's experience of rural and remote nursing. Sixth National Rural Health Conference. Retrieved September 30, 2009, from http://www.abc.net.au/health/papers/paper11.htm.

Chow, C. (2013) Mission possible? An analysis of Australian universities' missions. Doctoral dissertation, University of Newcastle, Australia.

Constructivism: From Phiolosopy to Practice, Retrieved 20 January 2014 at http://www.ucs.mun.ca/ emurphy/stemnet/ cle.html

Edward, C. (1999). Models for web-based instruction: A discussion of recurring themes. In K.E. Sparks \& M. Simonson (Eds.), Proceedings of the 21st National Convention of the Association for Educational Communications and Technology (pp. 319-321). Houston, TX: AECT.

Global Alliance for Transnational Education (1997) Certification Manual: Assuring the Quality of Education and Training which Cross National Borders. Global Alliance for Transnational Education.

Knight, J., 2004. Internationalization Remodeled: Definition, Approaches, and Rationales.JournalofStudiesin International Education, 8(1), pp.5-31. Available at: http://jsi.sagepub. com/cgi/doi/10.1177/1028315303260832

Knowles, M. ( 1980). The Modern Practice of Adult Education: From Pedagogy to Andragogy. Cambridge Book Co,New York.

Leask, B. (2014). Internationalizing the Curriculum and all Students' Learning, International Higher Education, No.78, Special Issue 2014, 5-6.

Mazzolini, M., Yeo, S., Giridharan, B., Goerke, V., Ling, P. and Lueckenhausen, G. (2012), Learning without borders, Office of Learning and Teaching, Australian Government, Canberra. http://tne.curtin.edu.au/project.html

McNamara, J., Knight, J. and Fernandez-Chung, R. (2013) The Shape of Things to Come: The evolution of transnational education: data, definitions, opportunities and impacts analysis. The British Council. Retrieved 20 January 2014 http://www.britishcouncil.org/sites/britishcouncil.uk2/ files/the_shape_of_things_to_come_2.pdf

Noddings, Nel (2005) Global citizenship: Promises and problems. In Nel Noddings (Ed.) Educating citizens for global awareness (pp.1-21). New York, Teachers College Press, Paris, 10-11 September 2001.

Quacquarelli Symonds (QS) (2014). Top Universities: Worldwide university rankings, guides and events. http://www. topuniversities.com/

Reeves, T.C., \& Laffey, J.M. (1999). Design, assessment, and evaluation of a problem-based learning environment in undergraduate engineering. Higher Education Research and Development Journal, 18(2), 219-232.

Rotter, J. B. (1966). Generalized expectancies for internal versus external control of reinforcement. Psychological Monographs, 80, 1-28.

Sivalingam, G. ( 2006). Privatization of Higher Education in Malaysia, Forum on Public Policy. Retrieved 3 August 2019 at https://files.eric.ed.gov/fulltext/EJ1098483.pdf

University Alliance (2014) Growing Global Graduates, Report, http://www.unialliance.ac.uk/wp-content/ uploads/2013/02/UA_global_grads.pdf

Van Damme, D.(2001). Higher Education in the Age of Globalization:The need for a new regulatory framework for recognition, quality assurance and accreditation, Introductory Paper for the UNESCO Expert Meeting.

Williams, R.D \& Lee, A. (Eds.) ( 2015). Internationalizing Higher Education, Sense Publishers: Rotterdam.

Yin, Robert K. (2013). Case Study Research: Design and Methods (5th ed.). Thousand Oaks, CA: SAGE Publications. 